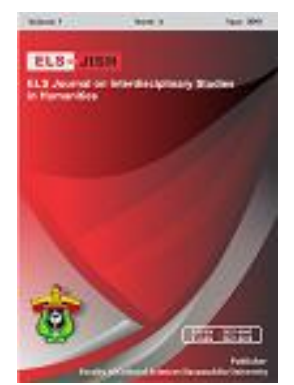

ELS-JISH

ELS Journal on Interdisciplinary Studies on Humanities

Volume 2 Issue 3, 2019

ISSN (print) : 2621-0843

ISSN (online) : 2621-0835

Homepage : http://journal.unhas.ac.id/index.php/jish

\title{
Students' Written Academic Discourse Competence and Difficulties in Writing Research Article for Publication
}

\author{
Dian Agustina Purwanto Wakerkwa ${ }^{1}$, Diah Kristina ${ }^{2}$, Dewi Rochsantiningsih ${ }^{3}$ \\ 1 dianapurwanto.w@gmail.com
}

\begin{abstract}
Publishing research article into a journal has recently been an obligation for many academicians around the globe. This demanding task require proper competence of written academic discourse. This study explored the difficulties faced by the students in the process of writing and submitting their articles into journals and how their competence of academic discourse played a role in this process. The data were gathered through the questionnaire and interview of ten Indonesian master students who were selected based on their writing and submitting research paper experience. Being a qualitative study, the findings of this study are presented and discussed narratively. The findings revealed a positive view of the students' basic competence of the written academic discourse for publication. Four difficulties were investigated as being experienced by the majority of the participants. Pedagogical implications are offered for the students for their future research publication.
\end{abstract}

Keywords: Academic Discourse, Research Article, Journal Publication, Writing for Publication, English Language Teaching

How to cite: Wakerkwa, D. A. P., Kristina, D., \& Rochsantiningsih, D. (2019). Students' Written Academic Discourse Competence and Difficulties in Writing Research Article for Publication. ELS Journal on Interdisciplinary Studies in Humanities, 2 (3), 439-451

\section{Introduction}

As the issue of writing for publication in higher education context becomes more and more demanding, all the members of the academic community are being pushed forward to produce more scientific works and published them into journals. It goes along with how the number of publication under one institution's name determine its credibility and research productivity as stated by Miller (2011). At the same time, the individual professional identity in the community is as well defined by this concern, academics are expected to play more varied forms of academic activity. It is supported by a statement proposed by Chichester \& Wool (2017), to gain professionalism in an academic discourse community, academician must contribute to the community advance practice by writing for peer-reviewed journals.

This writing research paper for publication in the Indonesian context, however, has been taken as one of the measurement aspects of a particular higher education

\footnotetext{
${ }^{1,2,3}$ Universitas Sebelas Maret, Indonesia 
setting's rank. Hong Kong likewise is also in the same state as the publication in international refereed journals determines the academic tenure and promotion (Flowerdew, 2000). Writing for publication is unlike writing any other paper. It requires relevance for professional field development (Robbins et al., 2016). Moreover, a decent comprehension of the academic discourse for publication is entailed. However, this basic necessary competence is somehow still being ignored by either the lecturers or the students. Numerous cases of research articles' rejection are attributable to the inadequacy of the writers on the notion of the aforementioned term.

According to Amnuai (2017), "each section of an RA displays different conventional format and style" (p. 1). The students need to keep in mind that, each section of an RA possess different communicative purposes. This communicative function is indicated by the moves implied within the text. Arsyad (2000) suggests that it is the author's strategy that makes the moves are arranged in a certain way in their texts. However, there are conventional norms in the application of the move structures, especially that of for publication purposes. Amnuai (2017) adds the importance of these conventions in the academic setting that the students should be made familiar with. A proper understanding of the rhetorical move structures of research paper for publication will enable the students to organize their work in the expected way of the academic community which leads to the increased chance of their manuscript for being accepted.

Not to ignore the countless number of research concerning in this issue of how writing for publication is still found hard for most academicians, however, one mainly focuses on the students' competence of academic discourse for publication particularly in Indonesian context is rare to be found. Hence, with the intent to answer this dearth, this research put the core focus into the Indonesian master students, in which their comprehensions of the rhetorical move structures of RA are explored, how they view this writing RA for publication and the difficulties they have on the writing and submitting process.

\section{Review of Related Literature}

To get a deep view on the term of academic discourse, let's borrow a very well stated statement from Burke (2010) where she argued that "each discipline has its way of doing things in using language" (p. 39). It emphasized how one discipline may differ one to another in how the language is used within its communication system. It can be pulled back to its relation with another definition of discourse community, according to Silver (2006) discourse community is "people working within particular area of knowledge with a shared repertoire of ideas and resources, who manifest their sense of community through the lexis, styles, ideologies, epistemological assumptions, etc. of their discourse over time" (p. 38). In this case, the academic context is used, in which it comes to the deduction that the academics are restricted in a specific way of doing language for academic publication.

Torn apart the term academic discourse, discourse itself related to the system of communication. Thus, academic discourse referred to a specific style of communication that is used among the members of the academic community. It is supported by Hyland (2011: 171) where he stated that "academic discourse refers to the ways of thinking and using language that exists in the academy." Speaking of 
discourse, the fact that both ways of communication are contained within, however, writing seems to be more complicated, as Paltridge (2006) purposed seven points that make written discourse more complex than spoken. One of which is its grammatical intricacy. It is even more confining when it comes to writing a research paper for publication. Each discourse community has its way of organizing its text that indirectly tying up the way the members manage to make sense of their written works.

With regards to the way the text is structured, further earlier, Halliday and Hasan (1976) were the first to see the many ways of how text can be organized. Later the pioneering work of Swales (1990) has opened a new sense of how the text must be designed where he investigated the Introduction section of the research article and proposed his now well-known CARS model. Following this work of Swales (1990), a few noble research have been carried out in various parts of the RA. For instance, Abstract (e.g., Hyland \& Tse, 2005), Introduction (e.g., Paltridge, 1994; Samraj, 2002; Samraj, 2005), Methods (e.g., Lim, 2006; Peacock, 2011; Musa et al., 2015), Results (e.g., Brett, 1994; Williams, 1999; Yang \& Allison, 2003), and Discussion (e.g., Holmes, 1997; Holmes, 2001; Peacock, 2002). Numerous research has focused on the other conventional features of academic written discourse as well, such as the use of indirectness markers (Hinkel, 1997), tenses and passive voice (Hinkel, 2004), and the use of personal pronouns (Doncheva-Navrátilová, 2013).

In addition to the yet restricted norms of the academic written discourse, journal publication ethics are as well demanding. The submitted manuscripts must at first be ensured whether the topics are of the journal's interest and appear to be on or even above the journal's standard for the quality of the content (Wolfe, 2000). This initial procedure is executed by the journal editor, before the manuscripts being sent to be peer-reviewed. Elliot (2018) suggested that many early academic writers look at this review process as "a somewhat daunting process" (p. 285). Not a little number of novice writers were being discouraged after receiving the revision comments (Chichester \& Wool, 2017). However, it is important to bear in mind that this review process brings about a beneficial feedback for the author, as stated by Robbins et al. (2016) that the comments of the reviewers "should be taken as helpful recommendations" for improving the significances and strength of their manuscripts (p. 253).

According to Felthous \& Wettstein (2014) that the value of research findings is one of the factors being considered by the reviewers, positive findings are valued more than the negative ones. Hence, the authors must be sure whether their research outcomes may give contributions to the field or not. It is in line with a statement from Moffat (2003) where he suggested two main criteria for publication to a journal, one of which is that the manuscript must in some way have a fair contribution to the knowledge, and it must not only offer a theoretical benefit but also being practically useful.

\section{Method}

This study explored to the extent to which the students comprehend the academic discourse for publication with respect to the term of rhetorical move 
structures of RA as well as the difficulties they had on the long process of writing and submitting the manuscript into a journal.

\subsection{Participants}

The participants of this study were ten master students from one of the universities in Indonesia. They were coming from various major studies and all of them have the experience of writing a research article, submitting it into a journal and being asked for revisions or even got a desk rejection by the journals' editors. The university where the participants were from established a requisite assignment for the master students in which to acquire their graduation degree, at least one RA must be published in an accredited journal under their name. The participants were referred here as S1 up to S10.

\subsection{Data Collection Technique}

The data in this study were gathered through a questionnaire and interview. The questionnaire was given to fifteen students, from these fifteen students ten were then selected based on their questionnaire responses. The questionnaire consisted of seventeen questions concerning their experiences and feelings towards the process of writing and submitting the article into a journal. Later the interview was carried out to the selected ten students. The open-ended interview was done to gain a deeper understanding of this concern.

\subsection{Data Analysis}

Being a qualitative study, the subjectivity of the authors may disrupt the validity and credibility of the findings. Hence, the method triangulation and member checking were used to meet these concerns. The data obtained from the participants were coded respectively according to the themes found from the questionnaire and interview. A similarity found in all participant was marked as one code. The data findings were presented in a narrative way to provide a deep and thorough picture of the students' understanding and view on the topic of this study.

\section{Findings}

The purpose of this study is to reveal the students' competence of academic discourse for publication and how this issue plays a role in the writing process of RA and in the process of submitting it into a journal. The findings are categorized respectively into a few subheadings below according to the codes found through the questionnaire and interview.

\subsection{Communicative Function of RA's Sections}

Each section of the RA possesses distinctive communicative functions. These functions are conveyed in a way that is generally approved within the discourse community. First of all, they have to know the basic format of RA, thus, they were asked about this concern. $100 \%$ of the participants can properly mention the sections of an RA as well as the information that should be included in each section. In some journals, the Introduction is combined with the Literature Review, while they are also written separately in other journals. Therefore, it is somehow quite challenging for the students to tell the difference between these two initial sections of the RA.

The Introduction covers the background of the study and the reasons of why the article is written. While Literature Review includes the previous studies done by 
other researchers that have the same scope with the present article and can be used as strong foundations for the ongoing study. (S5, June 29, 2019)

According to S5, in the Introduction the author must provide adequate information about what is the motivation behind the study and what makes it important. Whilst in the Literature Review, this background information is being supported by some related previous studies of the same scope. Another answer was obtained from other students.

Introduction consists of the background study and the rationale of why is the study need to be conducted, while the Literature Review includes the previous studies that discuss the same scope of topic to support the present study. (S3, June 29, 2019)

S3 explained the aspects that must be included in an Introduction and cannot be found in the Literature Review. S5 and S3 answers above show a clear knowledge of what makes the Introduction different from the Literature Review. The other two sections of RA that are also quite perplexing to be distinguished are Findings and Discussion. Various responses achieved from the students in this regard.

Findings are the analysis of the data, can be presented in the form of table and others while Discussion is the explanation the findings with the association to the previous studies and theories. (S8, June 29, 2019)

According to S8, the clear line between the Findings and Discussion is that Findings purely consists of the results of the study while on the other hand, in the Discussion, the results must be presented with the relation to the other previous related studies. S10 gave a similar reaction to this question.

The Findings consists of the results that answer the research questions, while the Discussion explains the findings with the relation to the prior studies. (S10, June 29, 2019)

S10's answer is in line with S8's, both of them gave a lucid distinction between the two adjacent sections of the RA. Knowing the communicative function of Discussion did not make it easy for the students to write it. As nine out of ten students found this section as the hardest one to write.

\subsection{Difficulties in the Process of Writing the RA}

Concerning the difficulties that occurred in the process of writing the RA for publication, there are some issues obtained from the students. The Issues are categorized into four types in this part based on their ratio of being experienced by the students of this study.

Table 1. Problems Faced and Feelings Felt by The Students in Dealing with the Issue of Writing RA

\begin{tabular}{ll}
\hline \multicolumn{1}{c}{ The Difficulties } & $\begin{array}{l}\text { No. of } \\
\text { Student }\end{array}$ \\
\hline Find the research topic & 6 \\
Find the research gap & 6 \\
Find the previous related literature & 5 \\
Limited time to find the research and & 5
\end{tabular}


Terrified of the review process

Afraid of being rejected by the journal 2

Table 1 above shows the problems faced and feelings felt by the students in dealing with the issue of writing RA and the number students who have experienced them. Four main problems faced by most of the students are presented below. These are the difficulty in findings the topic to write, finding the research gap, finding the related previous studies, and the limited time to conduct the research and write the results into paper. And one last part presents the students' view of what was the section in the RA that they found to be the most difficult to write.

\subsubsection{Find a topic to write}

All the students agree that the beginning is always the hardest. Finding an interesting topic which is currently being discussed in the community considered as the hardest first step by most novice writers particularly the students in this study. Six of ten students admitted having experienced this problem.

I struggled for the first time trying to write a research paper. I don't know what to

write, what topic I should discuss, and where to start. (S1, June 30, 2019)

It can be seen from $\mathrm{S} 1$ concession, that she was struggling the first time she tried to start doing the research. The similar response was obtained from the other five students as well.

I had some problems in doing my research. First, it took me a long time to find a good topic for my research ... (S2, June 30, 2019)

The responses from S1 and S2 above give an obvious depiction of the first step of finding a theme which is interesting enough to be researched was a challenging task. Not only that the topic must be in accordance with the research field but also it is better if the topic suits their interest.

\subsubsection{Find a Research Gap}

Finding the research gap was as well seen as a difficult phase for the majority of the participants in this study. Some of them admitted that it took them a long time to can finally detect the existing gap in the literature that worth researched. Not only they had to make sure that the topic they bring into their study is acceptable, but it should also make a contribution to the research field in general.

The first time I started to write, I was struggling to find the research gap to be explored. I needed quite a long time to read a lot of literature until I can finally come up with an idea for my research. (S3, June 29, 2019)

S3 said that he needed extensive time to be finally able to find the gap to be researched. It was done with a lot of readings and resuming. Another similar response was received from $\mathrm{S} 10$ as well.

It was really hard for me to identify the research gap from the literature. I can't remember how many papers I have read until I can find the gap for my research.

(S10, June 29, 2019)

Just like S3, S10 have to read a lot of research papers to be able to identify the existing gap in the field for their research. Different context from what has been done in the previous studies can be taken as a research gap, such as the different setting, 
the different targeted participants, and the different methods.

\subsubsection{Find Related Literature}

Most of the students in this study had difficulty in finding the existing literature related to their topics. Despite the massive number of either the printed or the online literature, they still find it hard to sort the most important and the most relatable ones.

Although I can find several papers related to my research theme in general, however, to find one that explicitly talks about the same context as mine is really hard. (S9, June 29, 2019)

Based on the answer above, S9 tried to search for some studies that discuss the same topic as his. Even though he finally able to found some, it took quite a long time to collect and select that literature. S6 had the same trouble as well.

One of the difficulties that I had was finding the paper of previous studies that have a relation with my research topic... (S6, June 28, 2019)

The response from S6 has proved that the students are still lack of the ability to detect the studies of other researchers that related to their research topic. And it became one of the obstacles they faced in the process of writing their RA.

\subsubsection{Limited Time for Doing the Research and Writing the RA}

Being an obligation for the graduation, the pressure of conducting research and write the findings in the form of a research paper seems extremely daunting for the students. They have to come up with a research topic, doing the research and writing the research findings into paper all these processes need a long time. Many students look at this entire process as a long laborious process. Five of ten students found this issue was very burdensome.

We must have a published research paper as one of the requirements for graduation. But for me, the time is not enough for the whole research, writing, and publishing processes. (S2, June 28, 2019)

Seen from S2 response above, the time available for doing all the steps in research is simply not enough. A longer time must be given to the students for them to be able to successfully publish their RA into a journal. Other four students have borne the same situation related to the time as well, one of which is $S 7$ in his confession below

We have to succeed in submitting our RA until it is published, but the time is very limited. That's why most of my colleagues cannot graduate on time because of this complicated task. (S7, June 29, 2019)

S7 statement emphasizes the fact that the limited time influenced the whole process. Looking at the confession of two students above, it can be confirmed that having enough time for conducting executing the entire process from the very beginning in finding the research topic until the last phase of successfully having the paper published in a journal is very crucial. Each student has a different level of intelligence and each of them may need a different range of time to finish this demanding task. However, as admitted by $S 7$ in his statement that most of his colleagues could not finished this publishing RA task time on time, as a result, they will have to take more semesters to graduate. 


\subsubsection{The Hardest Section to Write}

Consisted of a few sections, there must be some of the sections that were the most challenging for the students. Among all the section, the Introduction and the Discussion were found to be the most difficult to write by the majority of the participants. In the Introduction, the authors must come up with the rationales of the study, tell the discourse community that their topic is interesting and needed to be conducted. As well as to show how their research would contribute to the field development. It goes along with how they felt that the beginning is always the hardest.

On the other hand, the Discussion, nine out of ten students acknowledged this section as the most complex one. Moving from the Results to the Discussion requires a deep interpretation. It is where the authors try to persuade the readers by providing an ample yet vivid explanation upon the findings they attained from their research. In line with this fact, two students admitted to their experience of being criticized by the journal editors in their Discussion. The critics were emphasizing on how the Discussion was not very well organized and that it is lack of contribution.

\section{Discussion}

Academic discourse as suggested by Duff (2010), is not merely an entity but a social, cognitive, and rhetorical process and an accomplishment in the form of social practice, struggled by many members of the academic community. This struggle is even greater for the novices. One form of knowledge realization in the community is through the research report. Besides this concern of the importance of writing an RA in the community, it is also an obligatory assignment must be fulfilled by all the students in this study. Knowing the importance of having at least one published research article indeed gave a clear vision to the students' mind of how this matter must be taken seriously. However, this demanding task was not easy to be completed by all the students in this study. Various views towards writing RA for publication are presented by the students that lead to one conclusion that all of them see this writing task is different from other ordinary writing tasks. It entails a more stringent regulation on every aspect.

According to Lim (2006), RAs is believed as a genre with stringent academic requirements in terms of both textual and organization and linguistic choices (p. 283). In addition to Lim, Basturkmen (2012) suggests that RAs are constructed and expressed carefully to appeal to their respective discourse communities. These two statements emphasize the concern of how an RA must be written which is not only in the way expected by the research community, but also must appeal to the readers. Accordingly, most of the students in this study find writing and submitting a research paper into a journal as a big obstacle. It is an obligation that somehow they are desperate to avoid.

Each section of the RA holds distinctive communicative function, thus, they carry different information within. The academic writers have to make sure that their communications in their text are written in the appropriate style (Swales \& Feak, 1994) which is expected by the academic community. The findings of this study have proved the consciousness of the students in this very concern. They are aware of the fact that these different communicative functions offer a different level of complexity. The findings show that the majority of the students agree that the Discussion section 
was the most complex one to write. The same idea was proposed earlier by Gastel \& Day (2016) where they argued that the faulty in the Discussion has been the main reason of the rejection of many papers, even though the research might be valid and interesting. Since the purpose of this section is to show the significance of the findings and to explain the meaning of the research findings to the readers (Hess, 2004). Therefore, it requires an ample yet vivid interpretation for the readers to be convinced of the research findings. In consequence, this section becomes the hardest one to compose. And this fact does not only proved by the confessions of the students in this study, yet this was as well confirmed by a few research such as Flowerdew (1999, 2001), Swales (1990), and Swales \& Feak (2004).

For the difficulties occurred in the process of composing the RA, the findings of the study revealed that majority of the students struggled in the attempt to detect the existing research gap. An interesting topic alone is not enough yet, the research must fill in the gap and make a contribution to the field development. As stated by Robbins et al. (2016), writing paper for publication must have the relevance for the professional field and at once bring new knowledge to the field. Two main difficulties experienced by most of the students in this study are in line with the findings of Hodges (2004). According to Hodges (2004), this task of publication is considered too difficult by the students, the lack of time and the problem in finding the research topic to write along with the fear of being rejected by the journal are the major factors that impede the students in writing for publication (cited in Kapp \& Albertyn, 2008). Six out of ten students were having a problem to find out what to write and which gaps that were available to be researched in the field. Successfully discerning the existing gap was a phase, the limited time provided for them to complete the entire task was another problematic phase. As a result, these hindrances could further restrain the students into achieving the goal of publication (Morss \& Murray, 2001 cited in Kapp \& Albertyn, 2008).

In addition to the aforementioned obstacles, in the writing process, there must be some sections seen as being the most complex ones to write. Turns out, the Introduction and the Discussion are the main problems. In the Introduction, they were struggling to make an averment upon the research questions they are proposing. Since they must show the importance of their study and propose their research problems with the support of the previous related studies. As stated by Gastel \& Day (2016) that the Introduction must provide sufficient information to allow the readers to understand the present study without needing to turn to previously published research papers on the same topic. The Introduction being a problem is in line with a statement of Swales \& Feak (1994) where they mention that it is widely known that the writing of this section can be difficult and problematic for many writers. The Discussion is even more troublesome than the Introduction as almost all the students in this study confessed to this section is the hardest one. This finding is supported by Amnuai \& Wannaruk (2013) in which they argue based on the previous studies they viewed that, it is difficult not only for non-native speakers but also for native speakers. It may be because they must present it in the persuasive and argumentative styles with the references to the prior research (Pojanapunya \& Todd, 2011)

\section{Conclusion and Recommendations}

This study proves that many students agree and consider the RA's publication 
process as daunting and nerve-wracking. From the time in seeking of the ideas, finding the previous related studies, identifying the existing gap, to the process of composing the ideas into a written form and up to the publication process. It leads to a great number of difficulties that emerge throughout the process. The majority of the participants admit that the beginning is always the hardest, finding the existing gap is very complicated as well as not being supported by an adequate amount of time have affected the entire process. For this concern, the assistance of the lecturers is highly suggested to guide the students in identifying the slight gap which may be appealing yet significant to be explored. Other obstacles may as well be overcome by being more exposed to the existing literature, and writing is hard it can be mastered only by writing more and more.

Furthermore, great attention must be paid to the students' development of academic written discourse for publication, how they comprehend the expected writing style of a research paper and what are the challenges they face in the whole process. Having the information about the potential hindrance which may merge during the process can be very helpful for both the lecturers and the students. It may ease the initial process by having the preceding vision of what should be done and what should be avoided. Another beneficial way to increase the students' understanding of this issue is to encourage them to be more involved in various academic activities such as participating in international seminars or conferences. Lastly, this present study is limited in the scope of ten master students in the context of Indonesian higher education, thus, what has been attained here should not be generalized into other settings, cultures, and disciplines. A various number of related problems in the case of writing RA for publication with a larger scope of study objects are still vital and interesting to be explored. Then again, the strategies to overcome the potential difficulties in this whole process need to be developed in further research.

\section{References}

Amnuai, W. (2017). The textual organization of the discussion sections of accounting research articles. Kasetsart Journal of Social Sciences, 1-6. https://doi.org/10.1016/j.kjss.2017.10.007

Amnuai, W., \& Wannaruk, A. (2013). Investigating move structure of English applied linguistics research article discussion published in international and Thai journals. English Language Teaching, 6(2), 1-13.

Arsyad, S. (2013). A genre-based analysis on discussion section of research article in Indonesian written by Indonesian speakers. International Journal of Linguistics, 5(4), 50-70.

Basturkmen, H. (2012). A genre-based investigation of discussion sections of research articles in dentistry and disciplinary variation. English for Academic Purposes, 11, 134-144.

Brett, P. (1994). A genre analysis of the results section of sociology articles. English for Specific Purposes, 13, 47-59.

Burke, S. B. (2011). The construction of writer identity in the academic writing of Korean ESL student: A qualitative study of six Korean students in the U.S. 
(Doctoral dissertation, Indiana University of Pennsylvania). Retrieved from http://knowledge.library.iup.edu/etd/635

Chichester, M. \& Wool, J. (2017). Before journal submission, build your own peer review board. Nursing for Women's Health, 21(2), 137-141.

Dontcheva-Navrátilová, O. (2013). Authorial presence in academic discourse: Functions of author-reference pronouns. Linguistica Pragensia, 1, 9-30.

Duff, P. A. (2010). Language socialization into academic discourse communities. Annual Review of Applied Linguistics, 30, 169-192.

Elliot, C. (2018). Responding to editor and reviewer comments, and a tribute to Tracey Brown. Human Resource Development International, 21(4), 285-287. doi:10.1080/13678868.2018.1491117

Felthous, A. R., \& Wettstein, R. M. (2014). Peer review to ensure quality in forensic mental health publication. The Journal of the American Academy of Psychiatry and the Law, 42(3), 305-314.

Flowerdew, J. (1999). Writing for scholarly publication in English: The case of Hongkong. Journal of Second Language Writing, 8(2), 123-145. http://dx.doi.org/10.1016/S1060-3743(99)80125-8

Flowerdew, J. (2000). Discourse community, legitimate peripheral participation, and the nonnative-English-speaking scholar. TESOL Quarterly, 34(1), 127-150. doi: $10.2307 / 3588099$

Gastel, B., \& Day. R. A. (2016). How to write and publish a scientific paper (8th Ed.). California: Greenwood.

Halliday, M. A. K., \& Hasan, R. (1976). Cohesion in English. London: Longman.

Hess, D. R. (2004). How to write an effective discussion. Respiratory Care, 49(10), 1238-1241.

Hinkel, E. (1997). Indirectness in L1 and L2 academic writing. Journal of Pragmatics, 27, 361-386. doi.org/10.1016/S0378-2166(96)00040-9

Hinkel, E. (2004). Tense, aspect and the passive voice in L1 and L2 academic texts. Language Teaching Research, 8(1), 5-29. doi:10.1191/1362168804Ir132oa

Hodges, J. L. (2004). Write away. Internal Auditor, 111(6), 6.

Holmes, R. (1997). Genre analysis, and the social sciences: An investigation of the structure of research article discussion sections in three disciplines. English for Specific Purposes, 16(4), 321-337.

Holmes, R. (2001). Variation and text structure: The discussion section in economics research articles. ITL Review of Applied Linguistics, 131, 107-137. doi:10.1016/s0889-4906(96)00038-5

$\mathrm{Hu}$, J. (2010). The schematic structure of literature review in research articles of applied linguistics. Chinese Journal of Applied Linguistics (Bimonthly), 33(5), 15-27. 
Hyland, K. (2011). Academic discourse. In K. Hyland and B. Paltridge (Ed.), Continuum Companion to Discourse Analysis (pp. 171-184). London: Continuum International Publishing Group.

Hyland. K., \& Tse. P. (2005). Evaluative that constructions: Signaling stance in research abstracts. Functions of Language, 12, 39-64. doi:10.1075/fol.12.1.03hyl

Kapp, C. \& Albertyn, R. (2008). Accepted or rejected: Editors' perspectives on common errors of authors. Acta Academica, 40(4), 270-288. DOI: $10.1080 / 17521740802651252$

Lim, J. M. H. (2006). Method sections of management research articles: A pedagogically motivated qualitative study. English for Specific Purposes, 25(3), 282-309. https://doi.org/10.1016/j.esp.2005.07.001

Miller, A. N., Taylor, S. G., \& Bedeian, A. G. (2011). Publish or perish: Academic life as management faculty live it. Career Development International, 16(5), 422445.

Moffat, L. E. F. (2003). On publication in peer reviewed journals. UroOncology, 3(2), 81-83. doi:10.1080/1561095031000148781

Morss, K., \& Murray, R. (2001). Researching academic writing within a structured programme: Insight and outcomes. Studies in Higher Education, 26(1), 35-52.

Musa, N. F., Khamis, N., \& Zanariah, J. (2015). The structure of method section in engineering research articles. Asian Social Science, 11(17), 74-82. doi.10.5539/ass.v11n17p74

Ogunniyi, M. B. (1998). Publishing in international journals. Journal of the Southern African Association for Research in Mathematics, Science and Technology Education, 2(1), 1-12.

Paltridge, B. (1994). Genre analysis and the identification of textual boundaries. Applied Linguistics, 15(3), 288-299. https://doi.org/10.1093/applin/15.3.288

Paltridge, B. (2006). Discourse analysis: An introduction. London: Continuum

Peacock, M. (2002). Communicative moves in the discussion section of research articles. System, 30, 479-497. doi:10.1016/s0346-251x(02)00050-7

Peacock, M. (2011). The structure of the methods section in research articles across eight disciplines. Asian ESP Journal, 7(2), 99-124.

Pojanapunya, P., \& Todd, R. W. (2011). Relevance of findings in results to discussion sections in applied linguistics research. Proceedings of the International Conference: Doing research in applied linguistics. King Mongkut's University of Technology Thonburi and Macquarie University.

Robbins, S. P., Fogel, S. J., McLaughlin, H., Pomeroy, E. C., Busch-Armendariz, N., \& Staller, K. M. (2016). From the editor - publish, don't perish! Strategies for getting published in peer-reviewed journals. Journal of Social Work Education, 52(3), 251-257. http://dx.doi.org/10.1080/10437797.2016.1182399

Samraj, B. (2002). Introduction in research articles: Variation across disciplines. English for Specific Purposes, 21, 1-17. 
Samraj, B. (2005). An exploration of a genre set: Research article abstracts and introductions in two disciplines. English for Specific Purposes, 24(2), 141-156.

Silver, M. (2006). Language across disciplines. Towards a critical reading of contemporary academic discourse. Boca Raton: Brown Walker Press.

Swales, J. M. (1990). Genre analysis: English in academic and research settings. Cambridge: Cambridge University Press.

Swales, J. M. (2004). Research genres: Explorations and applications. Cambridge: Cambridge University Press.

Swales, J. M., \& Feak, C. B. (2012). Academic writing for graduate students: Essential tasks and skills (3rd Ed.). Ann Arbor: University of Michigan Press.

Yang, R., \& Allison, D. (2003). Research articles in applied linguistics: Moving from results to conclusions. English for Specific Purposes, 22(4), 365-385.

Williams, I. A. (1999). Results section of medical research articles: Analysis of rhetorical categories for pedagogical purposes. English for Specific Purposes, 18(4), 347-366.

Wolfe, A. (2000). Why did this journal reject your article? International Journal of Advertising, 19(1), 67-72. https://doi.org/10.1080/02650487.2000.11104784 